Revista Eletrônica do Mestrado em Educação Ambiental

Revista do PPGEA/FURG-RS

ISSN $1517-1256$

Programa de Pós-Graduação em Educação Ambienta1

\title{
Educação Ambiental na Gestão Pública: O processo de construção da Política de \\ Desenvolvimento Sustentável da Pesca no Estado do Rio Grande do Sul - Brasil
}

\author{
Ederson Pinto da Silva ${ }^{1}$ \\ Universidade Federal do Rio Grande \\ https://orcid.org/0000-0002-6917-2674 \\ Lucia de Fátima Socoowski de Anello ${ }^{2}$ \\ Universidade Federal do Rio Grande \\ https://orcid.org/0000-0002-9139-9584
}

Resumo: O presente trabalho é parte integrante de uma pesquisa de doutorado que busca analisar a Educação Ambiental presente no processo de construção da Política de Desenvolvimento Sustentável da Pesca no Estado do Rio Grande do Sul - Brasil. Partindo do conflito ambiental que opôs, de um lado, os barcos industriais de arrasto e, de outro, pequenos armadores de pesca de emalhe e pescadores artesanais da zona costeira, analisa, na perspectiva marxiana e freireana, a práxis educativa e o método presentes no processo de constituição do sujeito coletivo e na transformação do conflito em potencialidade de transformação da realidade por meio da Gestão Pública. Conclui a análise evidenciando a importância do método como visão de mundo que fundamenta a postura adotada pelo educador ambiental em processos tensionados no contexto de conflitos ambientais.

Palavras-chave: Educação Ambiental. Gestão Pública. Pesca

\section{Educación Ambiental en la Gestión Pública: el proceso de construcción de la}

\section{Política de Desarrollo Sustentable de la pesca en el Estado de Río Grande del Sur- \\ Brasil}

\footnotetext{
${ }^{1}$ Bolsista CAPES. Doutorando no Programa de Pós-Graduação em Educação Ambiental da Universidade Federal do Rio Grande. Mestre em Gerenciamento Costeiro pela mesma instituição (2017). Possui graduação em Tecnologia em Gestão Ambiental pelo Centro Federal de Educação Tecnológica de Pelotas (2008) e Especialização em Gestão Pública pela Universidade Federal do Rio Grande do Sul (2015). e-mail: ederson.tga@ gmail.com

2 Docente no Programa de Pós-Graduação em Educação Ambiental da Universidade Federal de Rio Grande. Possui graduação em Licenciatura Plena em Educação Física em pela Universidade de Caxias do Sul (1983), mestrado e doutorado em Educação Ambiental pela Universidade Federal do Rio Grande. Tem experiência na área de Educação, com ênfase em Educação Ambiental, atuando principalmente nos seguintes temas: Educação Ambiental, licenciamento, política pública, gestão ambiental e ambiente. e-mail: luciaanello@hotmail.com
}

Rev. Eletrônica Mestr. Educ. Ambient. Rio Grande. v. 37, n. 1. Seção especial: XI EDEA - Encontro e Diálogos com a Educação Ambiental. p. 247-263. jan/abr. 2020.

E-ISSN 1517-1256 
Resumen: El presente trabajo es parte integrante de una investigación de doctorado que busca analizar la Educación Ambiental presente en el proceso de construcción de la Política de Desarrollo Sustentable de la Pesca en el Estado de Río Grande del Sur- Brasil. Partiendo del conflicto ambiental que opuso, de un lado a los barcos industriales de arrastre y del otro, a los pequeños armadores de la pesca de enmalle y pescadores artesanales de la zona costera; analiza, en la perspectiva marxiana y freireana, la praxis educativa y el método presente en el proceso de constitución del sujeto colectivo y en la transformación del conflicto en potencial para convertir la realidad por medio de la Gestión Pública. El análisis concluye evidenciando la importancia del método como visión del mundo que fundamenta la postura adoptada por el educador ambiental en procesos tensos en el contexto de conflictos ambientales.

Palabras clave: Educación ambiental - Gestión pública - Pesca

\title{
Environmental Education in Public Management: The process of building the
} Sustainable Fisheries Development Policy in the State of Rio Grande do Sul - Brazil

\begin{abstract}
This paper is part of a doctoral research aimed to analyze the Environmental Education present in the construction process of the Sustainable Fisheries Development Policy in the State of Rio Grande do Sul - Brazil. As a starting point, the environmental conflict that opposes, on the one hand, industrial trawlersand, on the other, artisanal fishermen working in the coastal zone is taken, whereas the educational praxis and the method present in the process of collective subject constitution and in the transformation of conflict into potentiality of reality transformation through Public Management are examined from the Freirean and Marxist perspectives. The importance of the method is highlighted as aninstance adopted by the environmental educator in tensioned processes involving environmental conflicts.
\end{abstract}

Keywords: Environmental Education - Public Management - Fisheries

\section{Introdução}

O presente trabalho é parte integrante de uma pesquisa de doutorado que busca analisar a Educação Ambiental presente no processo de construção da Política de Desenvolvimento Sustentável da Pesca no Estado do Rio Grande do Sul - Brasil, criada como resposta ao conflito ambiental envolvendo pescadores artesanais, pequenos armadores de pesca de emalhe e a pesca industrial de arrasto. Neste sentido, Acselrad (2010) identifica a existência de uma razão utilitária hegemônica que estrutura sua estratégia para lidar com a questão ambiental pela lógica do Mercado, atribuindo as soluções de tais questões ao progresso científico e ao consenso político, atuando em um campo estratégico onde "uma revolução da eficiência é evocada para economizar o planeta, dando preço ao que não tem preço” (ACSELRAD, 2010, p. 109). Sua análise demonstra que há uma estreita ligação entre as questões ambientais e a estrutura de classes da sociedade. O autor chega a uma síntese de que cada vez mais a proteção ambiental passa a ser parte integrante das lutas sociais das ditas maiorias, pois, no modelo atual, para que grupos hegemônicos fiquem com os benefícios da exploração da natureza, aos grupos

Rev. Eletrônica Mestr. Educ. Ambient. Rio Grande. v. 37, n. 1. Seção especial: XI EDEA - Encontro e Diálogos com a Educação Ambiental. p. 247-263. jan/abr. 2020. 
sociais mais fragilizados é delegada a árdua tarefa de arcar com os impactos ambientais decorrentes deste modelo societário.

Se de um lado as relações sociais de produção baseadas na exploração do trabalho pelo Capital levam a desigualdades sociais, do ponto de vista ambiental a soma das relações sociais de produção com as relações sociedade-natureza leva às desigualdades ambientais, ou seja,

a exposição desproporcional dos socialmente mais desprovidos aos riscos das redes técnico-produtivas da riqueza ou sua despossessão ambiental pela concentração dos benefícios do desenvolvimento em poucas mãos[...](ACSELRAD, 2010, p. 109).

Estando estreitamente ligadas às desigualdades sociais geradas pela organização social hegemônica, as desigualdades ambientais acabam se transformando em injustiças ambientais, ou seja, a forma como em sociedades desiguais os recursos ambientais são concentrados sob o poder de grandes interesses econômicos, destinando a maior carga dos custos ambientais do desenvolvimento para as camadas mais vulneráveis da sociedade, como populações de baixa renda, classe operária e grupos étnico-raciais marginalizados (ACSELRAD, 2003).

Em determinados casos, as injustiças ambientais passam a ser percebidas pelos grupos sociais impactados, que reagem, dando origem aos chamados conflitos ambientais, que, em síntese, podem ser caracterizados como

aqueles envolvendo grupos sociais com modos diferenciados de apropriação, uso e significação do território, tendo origem quando pelo menos um dos grupos tem a continuidade das formas sociais de apropriação do meio que desenvolvem ameaçada por impactos indesejáveis - transmitidos pelo solo, água, ar ou sistemas vivos decorrentes do exercício das práticas de outros grupos. O conflito pode derivar da disputa por apropriação de uma mesma base de recursos ou de base distintas, mas interconectadas por interações ecossistêmicas [...]. Este conflito tem por arena unidades territoriais compartilhadas por um conjunto de atividades cujo "acordo simbiótico" é rompido em função da denúncia dos efeitos indesejáveis da atividade de um dos agentes sobre as condições materiais do exercício das práticas de outros agentes. (ACSELRAD, 2004 p.26)

No Brasil, a implementação de uma política pesqueira que canalizou vultosos recursos para o desenvolvimento de uma pesca empresarial capitalista, a qual passou a ser implementada a partir da criação da SUDEPE e da publicação do Decreto-Lei 221/1967, 
impactou de forma determinante as comunidades de pesca artesanal. Fruto desta política, tais comunidades passaram a sofrer sistematicamente com o desequilíbrio ambiental dos ecossistemas costeiros e com a devastação dos estoques pesqueiros, em decorrência da ação de grandes embarcações agregadas de tecnologia, sobretudo pela pesca de arrasto e seu duplo impacto simultâneo sobre o substrato do fundo do mar e sobre os juvenis de peixes (DIEGUES, 1988). A Zona Costeira do estado do Rio Grande do Sul não foi exceção a este processo! Ao longo dos anos, a ação intensa de embarcações industriais de arrasto sobre a faixa marítima passou a se constituir como uma fonte de ameaças para as comunidades pesqueiras presentes no território (SILVA; WALTER, 2017).

Diante das ameaças ao seu modo de vida, as comunidades de pescadores artesanais passaram a denunciar os impactos causados no território pela ação da pesca empresarial capitalista, dando origem a diversas lutas, muitas delas realizadas em conjunto com os armadores e pescadores da frota de emalhe baseada nos municípios de Rio Grande e São José do Norte, um grupo social intermediário no processo de modernização, com características também intermediárias no que se refere a organização social da produção e ao emprego de tecnologia, o qual também passou a ser amplamente impactado pela ação das grandes embarcações. Não raras as vezes, estas lutas estiveram relacionadas a normas de gestão que tratavam como iguais os diferentes grupos sociais que disputavam o acesso aos estoques pesqueiros, gerando injustiças com a pesca artesanal (SILVA; WALTER, 2017).

Neste contexto, nas duas primeiras décadas do século XXI a Zona Costeira do Rio Grande do Sul passou a se constituir em um território com diversos conflitos envolvendo a pesca artesanal, eventualmente em associação com os pequenos armadores de pesca, e a pesca empresarial capitalista. Como exemplo destes conflitos, podem ser citados:

i) o conflito relacionado com a atuação da frota de traineiras sobre o estoque de corvina (Micropogonias furnieri), que inicialmente resultou na proibição de atuação desta frota da região adjacente aos Molhes da barra de Rio Grande e, posteriormente, na proibição das traineiras capturarem a espécie (IBAMA, 2003; 2007);

ii) o conflito gerado pela publicação da Instrução Normativa Interministerial MPA/MMA $n^{\circ}$ 10/2011 que, na prática, inviabilizou a captura comercial de anchova (Pomatomus saltatrix) pelas embarcações da pesca artesanal e dos armadores do emalhe costeiro, possibilitando, no entanto, autorização complementar para embarcações de arrasto e de cerco (traineiras) explorarem comercialmente a mesma espécie. Conflito este que se estendeu até 2013 quando, após intensas manifestações de pescadores artesanais e 
armadores, o Governo Federal publicou uma portaria que possibilitou com que as embarcações do emalhe costeiro e da pesca artesanal voltassem a praticar a pesca da anchova (MPA; MMA, 2013);

iii) o conflito envolvendo o Plano de gestão para o uso sustentável da tainha (Mugil liza Valenciennes, 1836) no Sudeste e Sul do Brasil, publicado em 2015, que criou uma série de ameaças para a pesca artesanal ao mesmo tempo em que garantiu acesso irrestrito ao estoque de tainha pela pesca industrial (WALTER et al, 2018);

iv) o conflito envolvendo, de um lado, comunidades de pescadores artesanais e pequenos armadores do emalhe, de outro a frota industrial de arrasto. Conflito este que se arrastou por décadas e que teve seu ponto de ebulição em meados da segunda década do século XXI, com a mobilização de lideranças da pesca artesanal e do emalhe, que passaram a reivindicar ações para evitar os impactos socioambientais causados pela pesca de arrasto junto a Zona Costeira, atividade que, até então, tinha como último regramento uma portaria publicada ainda durante o regime militar (SUDEPE, 1983).

No tocante ao conflito com a pesca industrial de arrasto, após diversos anos sem obter sucesso, os pescadores artesanais e pequenos armadores de pesca de emalhe passaram a se articular para encontrar uma forma de afastar a pesca de arrasto da Zona Costeira. Assim, teve início um processo de luta e mobilização, que no ano de 2018 culminou com a publicação da Lei estadual $n^{\circ} 15.223 / 2018$, proibindo a pesca de arrasto em todo o território do Rio Grande do Sul, incluindo o seu mar territorial (RIO GRANDE DO SUL, 2018).

Cabe registrar que durante este processo um dos autores atuou na construção de processos dialógicos com as lideranças, com o objetivo de definir e executar a ação estratégica a ser implementada pelas lideranças dos pescadores artesanais e dos armadores de pesca de emalhe. Diante do exposto, o presente artigo busca, na práxis educativa do trabalho realizado durante este processo com pescadores artesanais e armadores, desenvolver uma análise a partir da compreensão do conflito em sua concretude e avançando sobre o método pedagógico para então discutir os resultados alcançados pelos pescadores.

\section{Aspectos teóricos e metodológicos para compreensão do processo}

Ao finalizar a apresentação da articulação entre as categorias econômicas, antes de entrar na exposição do método que o permitiu analisar a sociedade burguesa, Marx deixa

Rev. Eletrônica Mestr. Educ. Ambient. Rio Grande. v. 37, n. 1. Seção especial: XI EDEA - Encontro e Diálogos com a Educação Ambiental. p. 247-263. jan/abr. 2020.

E-ISSN 1517-1256 
aberta a possibilidade de utilização de seu método para "qualquer todo orgânico" (MARX, 2011, p.76). Na exposição do método que possibilita o conhecimento da realidade por meio da totalidade concreta, afirma que

\begin{abstract}
se eu começasse pela população, esta seria uma representação caótica do todo e, por meio de uma determinação mais precisa, chegaria analiticamente a conceitos cada vez mais simples; do concreto representado [chegaria] a conceitos abstratos [Abstrakta] cada vez mais finos, até que tivesse chegado às determinações mais simples. Daí teria de dar início à viagem de retorno até que finalmente chegasse de novo à população, mas desta vez não como a representação caótica de um todo, mas como uma rica totalidade de muitas determinações e relações [...] O concreto é concreto porque é a síntese de múltiplas determinações, portanto, unidade da diversidade. Por essa razão, o concreto aparece no pensamento como processo da síntese, como resultado, não como ponto de partida, não obstante seja o ponto de partida efetivo e, em consequência, também o ponto de partida da intuição e da representação. (MARX, 2011, p. 77-78)
\end{abstract}

Tambara e Oliveira (2011) afirmam que os raciocínios metodológicos presentes no "método da economia política" podem ser utilizados para a investigação de qualquer realidade complexa. Desta forma, afirmam que "pode-se, portanto, compreender o método da Economia Política como o método da Educação, da História, da Sociologia etc." (TAMBARA; OLIVEIRA, 2011, p. 151).

Nesta perspectiva teórica, ao se analisar um conflito ambiental presente em determinado território, o método de Marx pode ser utilizado de forma a possibilitar o conhecimento do conflito em sua concretude. Assim, partindo do conflito como uma "representação caótica do todo" seria necessário analisá-lo no contexto das relações sociais de produção existentes no território, considerando ainda que tanto o território como as relações que nele ocorrem e que geram o conflito, são pertencentes a um todo orgânico que se articula dialeticamente com suas partes em um movimento dinâmico. Desta forma, para a compreensão do conflito em questão, bem como para a compreensão do método presente nas ações executadas, são necessários dois movimentos analíticos iniciais.

O primeiro movimento corresponde a uma análise do conflito em si, buscando compreender como um conflito regional pelo acesso aos estoques pesqueiros presentes no território se articula com a totalidade da pesca, tanto em nível estadual como em nível nacional. Ainda faz parte deste movimento buscar compreender como, em uma escala mais geral, o conflito se articula com o modelo de produção hegemônico que, conforme Santos (2006; 2008) impõe suas verticalidades aos territórios, levando a ressignificações nas

Rev. Eletrônica Mestr. Educ. Ambient. Rio Grande. v. 37, n. 1. Seção especial: XI EDEA - Encontro e Diálogos com a Educação Ambiental. p. 247-263. jan/abr. 2020. 
relações sociais de produção no nível local. Para tanto, um bom caminho é a análise da pesca no Brasil a partir de Diegues $(1973 ; 1983 ; 1988)$, pois suas formulações ultrapassam a barreira da gestão pesqueira e possibilitam compreender a pesca em sua totalidade, tendo como referência o movimento histórico das forças produtivas do modelo de produção. Para Diegues, "a categorização de indivíduos numa atividade econômica é uma função, em $1^{\circ}$ lugar da especificidade do setor, de seu dinamismo e das condições em que é realizado e, em $2^{\circ}$ lugar, da estrutura social em que a atividade se insere" (DIEGUES, 1973, p. 110).

Desta forma, sugere alguns critérios para a estratificação dos pescadores em categorias, tais como: i) relações de trabalho existentes na unidade produtiva; ii) destino da produção; iii) tecnologia utilizada; iv) ambiente ecológico a ser explorado, e v) tradição de pesca. Assim, ao categorizar os pescadores do litoral de São Paulo, deixando aberta a possibilidade de utilização de suas categorias para outras realidades ao longo do litoral brasileiro, Diegues parte da análise das relações entre os agentes da produção pesqueira, para apresentar algumas formas e subformas em que se expressa.

[...] percebe-se que os agentes da produção pescadores/não-pescadores se relacionam entre si e com as condições objetivas da produção, segundo certas formas ou modelos que ganham uma existência histórica. Ainda que em dados momentos históricos uma dessas formas seja a dominante, a mais dinâmica, elas coexistem e se articulam. Tendo-se em vista as diversas combinações dos fatores produtivos em relações sociais de produção, constatamos que elas assumem formas possíveis e algumas subformas: a) a produção pesqueira de autossubsistência ou primitiva; b) a produção pesqueira realizada dentro dos moldes da pequena produção mercantil; c) a produção pesqueira capitalista. No interior da pequena produção mercantil identificamos ainda duas subformas: a) a pequena produção familiar dos pescadores-lavradores, e b) a pequena produção dos pescadores artesanais. No interior da produção pesqueira capitalista encontramos duas subformas: a produção dos armadores de pesca e a produção das empresas de pesca. (DIEGUES, 1983, p. 148)

Entretanto, há de se chamar a atenção para uma importante particularidade da pesca, a qual deve ser considerada. O próprio Diegues (1983) destaca que, como uma atividade que vive da exploração direta da natureza, onde há uma importante relação entre a reprodução social e a reprodução natural, na pesca há uma correlação entre a reprodução da vida social e a reprodução biológica dos estoques de pescado. No tocante à pesca artesanal, esta correlação, quando associada ao limite territorial de atuação, afeta de forma considerável a reprodução social nas comunidades. Porém, ainda que a pesca capitalista 
tenha maior mobilidade, os limites de captura também estariam estreitamente ligados à capacidade de reprodução dos estoques.

Este seria "um aspecto importante na análise da atividade pesqueira, esquecido muitas vezes por aqueles que analisam a pesca como idêntica aos outros setores da divisão social de produção" (DIEGUES, 1983, p. 95). Assim, no contexto do conflito em questão, a aliança entre pescadores artesanais e armadores de pesca para afastar o arrasto industrial para fora da zona costeira não é movida por uma identidade social. Esta se dá na medida em que as duas formas de produção passam a sofrer com os impactos gerados por uma frota que representa um outro grupo social, mais desenvolvido do ponto de vista das forças produtivas: o arrasto industrial. Ao operar no território, o arrasto industrial gera impactos sobre o ecossistema e sobre os estoques pesqueiros de forma a pôr em risco a reprodução social, tanto dos pescadores artesanais como dos pequenos armadores de pesca de emalhe. Ainda que estes impactos ao longo dos anos tenham sido denunciados por pescadores artesanais e armadores, o arrasto industrial, por possuir maiores recursos poder, historicamente conseguiu manter sua ação legitimada pelos instrumentos públicos de gestão pesqueira. Sobre recursos de poder, Rua (2009) traz uma importante definição para este termo ao afirmar que estes

\begin{abstract}
são capacidades que um ou vários atores podem utilizar para pressionar por decisões que sejam favoráveis aos seus interesses. Podem envolver desde reputação, posição social, contato com redes de influência, controle de dinheiro, de armas, capacidade de denunciar e chantagear, inserção internacional, poder de mobilização de grandes grupos (greves, manifestações sociais), controle de recursos tecnológicos (meios informatizados de operação de bancos de dados etc.), capacidade de infligir prejuízos (obstrução de estradas, de aeroportos, greves etc.). Os recursos de poder são os elementos que sustentam as alianças e as barganhas ou negociações em torno de uma política pública. (RUA, 2009, p. 44)
\end{abstract}

Já o segundo movimento consiste em analisar a conjuntura da arena política relacionada ao conflito em questão, dando especial atenção para o Conselho Gaúcho de Aquicultura e Pesca Sustentáveis - CONGAPES. Cabe registrar que a luta de pescadores artesanais e armadores contra os impactos causados pela pesca de arrasto industrial praticada na Zona Costeira já havia sido tratada na Câmara Técnica de Pesca do CONGAPES e que uma das propostas que esteve em discussão no Conselho foi a criação de uma Área de Proteção Ambiental - APA, compreendendo toda faixa marítima da Zona Costeira do Rio Grande do Sul. Tal proposta propunha que nesta área a pesca de arrasto

Rev. Eletrônica Mestr. Educ. Ambient. Rio Grande. v. 37, n. 1. Seção especial: XI EDEA - Encontro e Diálogos com a Educação Ambiental. p. 247-263. jan/abr. 2020.

E-ISSN 1517-1256 
industrial fosse proibida. Porém, a proposta da APA não foi bem recebida por representantes do setor, principalmente pelos pescadores artesanais da região sul do estado.

Neste sentido, considerando que os encaminhamentos para a mediação ou superação do conflito em questão, estão associados a ação do Estado como mediador, pode-se compreender tal conflito, como uma questão a ser tratada no âmbito da Gestão Ambiental Pública, entendida por Quintas (2006) como mediadora de conflitos entre atores que agem sobre os meios físico-natural e construído, com o objetivo de garantir o direito constitucional ao meio ambiente ecologicamente equilibrado. Quintas (2004) traz a Educação no Processo de Gestão Ambiental como uma concepção de Educação Ambiental que, reconhecendo a assimetria nas arenas políticas que tratam da Gestão Ambiental, atua no sentido de fortalecer os grupos sociais mais fragilizados para que os mesmos possam se inserir em melhores condições na disputa travada no âmbito destas arenas.

Por ser produzida no espaço tensionado, constituído a partir do processo decisório sobre a destinação dos recursos ambientais na sociedade, a Educação no Processo de Gestão Ambiental exige profissionais especialmente habilitados, que dominem conhecimentos e metodologias específicas para o desenvolvimento de processos de ensino-aprendizagem com jovens e adultos em contextos sociais diferenciados. Exige, também, compromissos com aqueles segmentos da sociedade brasileira, que na disputa pelo controle dos bens naturais do país, historicamente são sempre excluídos dos processos decisórios e ficam com o maior ônus. Cabe esclarecer que, ao se falar em Educação no Processo de Gestão Ambiental, não está se falando de uma nova Educação Ambiental. Está se falando sim, em uma outra concepção de Educação que toma o espaço da gestão ambiental como elemento estruturante na organização do processo de ensino-aprendizagem, construído com os sujeitos nele envolvidos, para que haja de fato controle social sobre decisões, que via de regra, afetam o destino de muitos, senão de todos, destas e de futuras gerações. (QUINTAS, 2004, p. 115-116)

Desta forma, ao mesmo tempo em que se reconhece a Gestão Ambiental Pública como um espaço tensionado e assimétrico, atribui-se à Educação Ambiental um importante papel para que os grupos sociais historicamente mais fragilizados nos processos decisórios possam se inserir de forma protagonista nas arenas que tratam da Gestão Ambiental Pública.

\section{A definição do sujeito da ação educativa e a escolha do método}

$\mathrm{Na}$ perspectiva de uma Educação transformadora, o método reflete a visão de mundo do educador e se expressa na postura e na intencionalidade do mesmo frente a 
determinada realidade. A ação pedagógica é entendida como um caminho a ser percorrido conjuntamente, por educador e educando, na construção de uma leitura crítica da realidade que se quer transformar, constituindo-se como um percurso para a consciência.

\begin{abstract}
A tomada de consciência não se dá nos homens isolados, mas enquanto travam entre si e no mundo relações de transformação, assim também somente aí pode a conscientização instaurar-se [...]. Este esforço da tomada de consciência em superar-se a alcançar o nível da conscientização, que exige sempre a inserção crítica de alguém na realidade que se lhe começa a desvelar, não pode ser, repitamos, de caráter individual, mas sim social. [...] a conscientização, que não pode dar-se a não ser na práxis concreta, nunca numa práxis que se reduzisse à mera atividade da consciência, jamais é neutra. (FREIRE, 1977, p. 77)
\end{abstract}

Assim, é imprescindível que o educador compreenda os educandos, e a si próprio, como sujeitos de sua práxis que "atuando, transforma; transformando, cria uma realidade que, por sua vez, envolvendo-o, condiciona sua forma de atuar" (FREIRE, 1977, p. 28). Na mesma linha, é importante que o educador ambiental comprometido com a transformação da realidade social tenha clareza de que seu papel enquanto sujeito constitui-se em "agir conscientemente em processos sociais que se constituem conflitivamente por atores sociais que possuem projetos distintos de sociedade, que se apropriam material e simbolicamente da natureza de modo desigual" (LOUREIRO, 2003, p. 42).

Neste sentido, Quintas (2004) destaca que na Educação no Processo de Gestão Ambiental os sujeitos prioritários da ação educativa devem representar os segmentos mais afetados e com menores condições de incidirem nos processos decisórios. Assim, observando-se o processo em questão, quando se considera a tipologia discutida por Diegues (1983), torna-se evidente que, em que pese a existência de uma aliança tática com os armadores, o sujeito da ação educativa se constituiu no grupo social dos pescadores artesanais.

Tendo os pescadores artesanais como sujeitos prioritários, o método foi desenvolvido de forma a criar os meios para dar voz aos pescadores artesanais por meio de um processo de construção participativa que possibilitou que estes assumissem o protagonismo na construção de uma alternativa para a transformação de sua realidade. Entretanto, quando se fala em construção participativa, é necessário que se compreenda a participação na perspectiva de Demo (2009), ou seja, como conquista, em um processo de luta que resulta, não só na participação em si, mas também em alterações na estrutura das desigualdades. Indo ao encontro desta concepção, Bordenave afirma que

Rev. Eletrônica Mestr. Educ. Ambient. Rio Grande. v. 37, n. 1. Seção especial: XI EDEA - Encontro e Diálogos com a Educação Ambiental. p. 247-263. jan/abr. 2020.

E-ISSN 1517-1256 
Numa sociedade regida mais pelos sistemas de interesses que pelos de solidariedade, com uma marcada estratificação socioeconômica, na qual umas classes exploram outras a participação será sempre uma guerra a ser travada para vencer a resistência dos detentores de privilégios. (BORDENAVE, 2013, p. 42)

Pode-se então considerar a participação efetiva dos pescadores artesanais como uma premissa fundamental na articulação do método e na definição das ações pedagógicas. Assim, para garantir tal premissa, o processo educativo trabalhou em três dimensões articuladas simultaneamente de modo a buscar o acúmulo de forças por parte dos pescadores: i) leitura crítica da realidade, posicionando no processo o sujeito coletivo pescador artesanal e articulando a aliança com os armadores de pesca; ii) conhecimento dos instrumentos de Gestão Pública existentes, passíveis de serem utilizados na perspectiva do grupo social dos impactados no conflito; iii) construção de uma estratégia de ação partindo dos pescadores em direção ao CONGAPES e ao governo.

\section{O método no processo de construção da Lei $\mathbf{n}^{0}$ 15.223/2018}

Buscando atender aos anseios dos sujeitos da ação educativa, foi construída uma estratégia executiva que teve o objetivo de partir de uma proposta construída pelos pescadores, possibilitando o acúmulo de forças para que a referida proposta chegasse até as estruturas de Estado. Contudo, considerando que a Gestão Pública, conforme afirma Matus (2005), é um processo dinâmico e de fim aberto, ao longo do percurso a estratégia executiva demandou alguns ajustes. Na sequência segue uma análise deste processo. Cabe registrar que não se busca descrever cada ação em si, mas analisá-las como parte de uma totalidade.

O Encontro Estadual de Pesca Costeira, realizado em Porto Alegre entre os dias 12 e 14 de dezembro de 2017 foi o ponto de partida e elemento central da estratégia para o desenvolvimento do processo. Tendo apoio de uma organização não governamental e sendo convocado por três organizações ligadas da pesca artesanal (Movimento dos Pescadores e Pescadoras - MPP; Comissão Nacional de Fortalecimento das Reservas Extrativistas Costeiras e Marinhas - CONFREM e Federação dos Sindicatos de Pescadores do Rio Grande do Sul - FESINPERS) e pelo Sindicato dos Armadores de Pesca do Rio Grande do Sul - SINDARPES, este encontro mobilizou lideranças das comunidades pesqueiras do litoral do Rio Grande do Sul para discutir a realidade da pesca frente aos 
impactos causados pela atuação do arrasto na faixa marítima da Zona Costeira. Tendo como tema pano de fundo o conflito, o objetivo deste encontro girou em torno da seguinte questão: como garantir o empoderamento dos pescadores nos processos de gestão pesqueira, de forma a buscar a adoção de medidas que visem a recuperação dos estoques pesqueiros?

Na Pedagogia do Oprimido Freire traz a seguinte reflexão:

Quem melhor que os oprimidos, se encontrará preparado para entender o significado terrível de uma sociedade opressora? Quem sentirá melhor que eles os efeitos da opressão? Quem, mais que eles, para ir compreendendo a necessidade de libertação? Libertação a que não chegarão pelo acaso, mas pela práxis de sua busca; pelo conhecimento e reconhecimento de sua necessidade de lutar por ela. (FREIRE, 2011, p. 42-43)

Neste sentido, como suporte ao método, a pedagogia freireana se constitui em estratégias didáticas, a exemplo de exposições dialogadas, discussões em grupos seguidas de debates em plenárias e dramatizações. Tal didática criou um ambiente propício para que os participantes se reconhecessem como sujeitos do processo de discussão, assumindo para si as definições do encontro. Assim, após três dias discussões, tendo os pescadores refutado definitivamente a proposta de criação de uma APA, quatorze organizações ligadas à pesca artesanal e uma ligada à pesca industrial assinaram a Carta de Porto Alegre, um documento que sintetizou os encaminhamentos do encontro em três pontos de luta:

i) criação de uma frente parlamentar na Assembleia Legislativa do RS; ii) criação de um código estadual de pesca sustentável que possa trazer a gestão pesqueira para o nível estadual; iii) fortalecimento do Conselho Gaúcho de Aquicultura e Pesca Sustentáveis - CONGAPES. (MPP et al., p.1, 2017).

Buscando acumular forças, o documento encerra convidando a se somarem na luta as lideranças representantes da pesca continental, bem como a sociedade gaúcha em geral. Cabe registrar que o estado do Rio Grande do Sul possui três fóruns regionais e diversas colônias de pescadores que atuam especificamente com a pesca continental.

No que se refere à criação da Frente Parlamentar, já havia uma aproximação de lideranças da pesca com um deputado estadual do Partido dos Trabalhadores. Assim, ao longo do encontro, na medida em que os debates rumaram para a necessidade de criação de uma lei estadual, as lideranças se articularam com o deputado, o qual se prontificou em 
trabalhar no legislativo para a criação de tal frente. No dia 21 de março de 2018 foi realizada a primeira reunião da "Frente Parlamentar em Defesa do Setor Pesqueiro no Rio Grande do Sul e pela Construção do Código Pesqueiro Sustentável Estadual", a qual foi instituída com a assinatura de 39, de um total de 55 deputados estaduais. Esta Frente Parlamentar, além de articular Poder Legislativo estadual, ainda iria realizar duas importantes reuniões nos dias 11 de junho, em Porto Alegre, e no dia 23 de julho em São José do Norte, município com maior número de pescadores do RS.

No que se refere ao Código Estadual de Pesca e ao fortalecimento do CONGAPES, a discussão com os pescadores levou a definição de uma estratégia de ação combinada entre momentos de discussão com os pescadores e momentos de articulação institucional. Assim, foi deliberada coletivamente uma estratégia de atuação que passou pelos seguintes momentos: i) elaboração de uma minuta de Projeto de Lei; ii) articulação com a Câmara Técnica da pesca do CONGAPES para a revisão da minuta e realização de um seminário institucional para a discussão da mesma; iii) validação da proposta junto ao grupo maior, e iv) articulação de uma reunião extraordinária do CONGAPES para a votação da proposta.

Para dar operacionalidade a tais deliberações foi eleito um grupo de lideranças, o qual teve a atribuição de articular as atividades e promover as articulações institucionais para viabilizar os encaminhamentos. Desta forma, para cada atividade realizada (reuniões, seminários e audiências públicas), o trabalho do educador foi planejar, pedagogicamente, o desenvolvimento das ações um processo socioeducativo de apreensão da realidade para então buscar transformá-la. Nesse sentido, estratégia didática se constituiu na utilização de técnicas e metodologias apropriadas aos objetivos definidos coletivamente com os pescadores.

Freire (1982, p. 48) afirma que "a consciência crítica dos oprimidos significa, pois, consciência de si, enquanto "classe para si". Neste sentido, paralelamente a estas atividades, pela sua práxis, os pescadores identificaram que a unidade construída ao longo do processo se converteu em uma potente ferramenta de pressão. A identificação e unificação enquanto "setor" possibilitou uma maior amplitude no que se refere aos recursos de poder passíveis de serem utilizados para fortalecer a proposta.

Ao se reconhecerem enquanto sujeito coletivo, sua palavra deixou de ser em seu nome, enquanto indivíduo, ou ainda apenas em nome de sua comunidade ou organização. Cada liderança passou a falar em nome do setor. Esta unidade e pertencimento em relação a proposta construída por eles em um processo participativo de fato, possibilitou com que o projeto de lei fosse aprovado por unanimidade em uma reunião do CONGAPES. Na 
mesma reunião, também foi aprovada uma resolução, solicitando ao Executivo Estadual que o projeto fosse encaminhado para a Assembleia Legislativa em regime de urgência.

Assim, em meio a pressões e mobilizações dos pescadores, no dia 21 de agosto de 2018 o projeto de lei foi aprovado por 46 votos a favor e nenhum contra. No dia 06 de setembro de 2018 foi publicada no Diário Oficial do Estado a Lei no 15.223/2018 que "Institui a Política Estadual de Desenvolvimento Sustentável da Pesca no Estado do Rio Grande do Sul e cria o Fundo Estadual da Pesca" (RIO GRANDE DO SUL, 2018).

\section{Considerações finais}

A reflexão realizada ao longo do presente trabalho parte da compreensão de um conflito ambiental vivenciado por pescadores artesanais, no qual, por meio da totalidade, é possível se conhecer sua concretude, passando pela discussão metodológica da Educação no Processo de Gestão Ambiental e chegando à análise particular de um processo desenvolvido com pescadores artesanais. Neste sentido, cabe destacar que, mesmo considerando que o processo desenvolvido percorreu um caminho de "fora para dentro" do Estado, ou que, por questões circunstanciais, contou com uma aliança entre pesca artesanal e armadores de pesca, a concepção de Educação na Gestão Ambiental esteve presente e serviu de fio condutor para a discussão da estratégia e das ações desenvolvidas ao longo do processo. Para a finalização da análise aponta-se duas questões identificadas ao longo da reflexão e que julga-se importantes para reflexões futuras.

A primeira questão está relacionada a contribuição que a Educação no Processo de Gestão Ambiental pode dar para a qualificação das políticas públicas de gestão pesqueira. Esta contribuição pode ser aportada na medida em que esta concepção de Educação Ambiental possibilita ultrapassar a barreira do olhar reducionista sobre o ato da captura, contribuindo para que os pescadores se compreendam na totalidade das relações de produção que determinam a realidade em que estão inseridos, e assim possam identificar formas de transformar sua realidade.

A segunda, que se articula com a primeira, diz respeito a necessidade de um aprofundamento na discussão de estratégias educativas que contribuam para que os pescadores artesanais possam se articular melhor para ocupar os espaços de participação existentes nas políticas públicas de gestão da pesca. Em que pese a gestão pesqueira seja atribuição do Estado, a discussão aqui abordada demonstra um processo no qual a política pública resultou da tomada de consciência, de organização e luta dos pescadores, sobretudo 
na identificação dos possíveis espaços de interação com o Estado para incidir em decisões que lhes digam respeito.

Por fim, sendo o presente trabalho parte de um todo que se articula em uma pesquisa de doutoramento focada na Educação no Processo de Gestão Ambiental com pescadores artesanais, cabe registrar que as reflexões desenvolvidas aqui em relação ao método, formaram a base para o aprofundamento ao longo da pesquisa. Neste sentido, considera-se importante aprofundar a discussão acerca da postura do educador ambiental comprometido com a transformação e do método desenvolvido com os pescadores artesanais.

\section{Referências}

ACSELRAD, Henri. Cuatro tesis sobre políticas ambientales ante las coacciones de la globalización. Nueva Sociedad, [S.I], v. 1, n. 188, p. 87-99, nov./dez. 2003. Disponível em: https://www.nuso.org/articulo/cuatro-tesis-sobre-politicas-ambientales-ante-lascoacciones-de-la-globalizacion/. Acesso em: 15 setembro 2019.

ACSELRAD, Henri. As práticas espaciais e o campo dos conflitos ambientais. In: Acselrad, H. (Org.). Conflitos Ambientais no Brasil. Rio de Janeiro: Relume-Dumará; Fundação Heinrich Böll, 2004, 296. p. 13-36.

ACSELRAD, Henri. Ambientalização das lutas sociais: o caso do movimento por justiça ambiental. Estudos Avançados, São Paulo, v. 24, n. 68, p.103-119. 2010. DOI: http://dx.doi.org/10.1590/s0103-40142010000100010. Disponível em: http://www.scielo.br/scielo.php?script=sci_arttext\&pid=S010340142010000100010\&lng=pt\&nrm=iso \&tlng=pt. Acesso em: 15 setembro 2019.

BORDENAVE, Juan E. Díaz. O que é participação. 8. ed. São Paulo: Brasiliense, 2013. 95 p. $6^{\text {a }}$ Reimpressão.

DEMO, Pedro. Participação é Conquista. 6. ed. São Paulo: Cortez, 2009. 176 p.

DIEGUES, Antônio Carlos Sant'Ana. Pesca e marginalização no litoral paulista. 1973. Dissertação (Mestrado em Ciências Sociais) - Departamento de Ciências Sociais, Universidade de São Paulo, São Paulo, 1973. Disponível em: http://nupaub.fflch.usp.br/sites/nupaub.fflch.usp.br/files/color/Pesca.pdf. Acesso em: 30 julho 2019.

DIEGUES, Antônio Carlos Sant'Ana. Pescadores, camponeses e trabalhadores do mar. São Paulo: Ática, 1983. 292 p.

DIEGUES, Antônio Carlos Sant'Ana. Formas de organização da produção pesqueira no Brasil: alguns aspectos metodológicos. In: ENCONTRO DE CIÊNCIAS SOCIAIS E O 
MAR NO BRASIL, 2. 1988, São Paulo. Coletânea de Trabalhos Apresentados. São Paulo: USP, 1988. v. 1, p. 1 - 39.

FREIRE, Paulo. Extensão ou comunicação? Rio de Janeiro: Paz e Terra, 1977. 93 p.

FREIRE, Paulo. Ação cultural para a liberdade e outros escritos. 7. ed. Rio de Janeiro: Paz e Terra, 1982. 149 p.

FREIRE, Paulo. Pedagogia do Oprimido. 50. ed. Rio de Janeiro: Paz e Terra, 2011. 253 p.

IBAMA. Portaria IBAMA n ${ }^{\circ}$ 80/2003, de 11 de dezembro de 2003. Brasília:IBAMA, 2003. Disponível em:

http://www.icmbio.gov.br/cepsul/images/stories/legislacao/Portaria/2003/p_ibama_80_200 3_areaexclusaopescacercoacessoaoestuariolagoapatos_rs.pdf. Acesso em: 12 setembro 2019.

IBAMA. Portaria IBAMA n ${ }^{\circ}$ 43/2007, de 24 de setembro de 2007. Brasília:

IBAMA, 2007. Disponível

em:http://www.icmbio.gov.br/cepsul/images/stories/legislacao/Portaria/2007/p_ibama_43_

2007_proibecapturacorvinaentreoutrasespeciespelaembarcacaocerqueira_se_s_altera_in_ib ama_135_2006.pdf. Acesso em: 12 setembro 2019.

LOUREIRO, Carlos Frederico Bernardo. Premissas teóricas para uma educação ambiental transformadora. Ambiente \& Educação, Rio Grande, v. 8, n. 1, p.37-57. 2003. Disponível em: https://periodicos.furg.br/ambeduc/article/view/897/355. Acesso em: 30 agosto 2019.

MARX, Karl. Grundrisse:Manuscritos econômicos de 1857-1858: esboços da crítica da economia política. Tradução Mario Duayer e Nélio Scheider. São Paulo: Boitempo, 2011. $1285 \mathrm{p}$.

MATUS, Carlos. Teoria do Jogo Social. Tradução Luís Felipe Rodrigues Del Riego. São Paulo: Fundap, 2005. 524 p.

Movimento dos Pescadores e Pescadoras (MPP) et al. Carta de Porto Alegre. Porto Alegre, 2017. 2 p.

MPA; MMA. Instrução NormativaMPA/MMA nº 04/2013, de 16 de outubro de 2013. Dispõe sobre critérios e padrões para a pesca de emalhe costeiro diversificado da anchova (Pomatomus saltatrix), corvina (Micropogonias furnieri), pescada (Cynoscion guatucupa), castanha (Umbrina canosai) e abrótea (Urophycis brasiliensis) praticada no litoral das regiões Sudeste e Sul. Brasília: MPA/MMA, 2013. Disponível

em:http://www.icmbio.gov.br/cepsul/images/stories/legislacao/Instrucao_normativa/2013/i n_mpa_mma_04_2013_crit\%C3\%A9rios_pesca_emalhe_costeiro_diversificado_anchova_ corvina_pescada_castanha_abr\%C3\%B3tea_se_s.pdf. Acesso em: 13 julho 2019.

QUINTAS, José da Silva. Educação no processo de gestão ambiental: uma proposta de educação ambiental transformadora e emancipatória. In: Layrargues, P. P. (Coord.) Identidades da educação ambiental brasileira. Brasília: Ministério do Meio Ambiente, 2004, 156. p. 113-140. 
QUINTAS, José Silva. Introdução à Gestão Ambiental Pública. 2. Ed. Brasília/DF: IBAMA, 2006, 100 p.

RIO GRANDE DO SUL. Lei Ordinária n⿳ 15.223, de 05 de setembro de 2018. Institui a Política Estadual de Desenvolvimento Sustentável da Pesca no Estado do Rio Grande do Sul e cria o Fundo Estadual da Pesca. Porto Alegre: Diário Oficial do Estado, [2018]. Disponível em: https://secweb.procergs.com.br/doe/public/downloadDiario/diariodownload-form.xhtml?dataPublicacao=2018-09-06\&nroPagina=5. Acesso em: 15 setembro 2019.

RUA, Maria das Graças. Políticas públicas. Brasília: CAPES/UAB, 2009. 130 p.

SANTOS, Milton. A Natureza do Espaço: Técnica e Tempo, Razão e Emoção. 4. ed. 2. Reimpressão. São Paulo: Editora da Universidade de São Paulo, 2006. 260 p.

SANTOS, Milton. Por uma outra Globalização: do pensamento único à consciência universal. 15. ed. Rio de Janeiro: Record, 2008. 174 p.

SILVA, Ederson Pinto da; WALTER, Tatiana. Pesca artesanal e conflitos ambientais: o caso da zona costeira do Rio Grande do Sul. Revista Caribeña de Ciencias Sociales, v. 1, p. 1-10, setembro. 2017. Disponível em: http://www.eumed.net/rev/caribe/2017/09/pescaartesanal-riogrande.html. Acesso em: 10 setembro 2019.

SUDEPE. Portaria SUDEPE nº N-26, de 28 de julho de 1983. Brasília: SUDEPE, 1983. Disponível em:

http://www.icmbio.gov.br/cepsul/images/stories/legislacao/Portaria/1983/p_sudepe_26_n_ 1983_regulamentapetrecho_areaexclusaoarrasto_rs_alterada_p_ibama_445_1989_p_sudep e_57_1983.pdf. Acesso em: 12 setembro 2019.

TAMBARA, Elomar; OLIVEIRA, Avelino Rosa de. Fontes e Métodos na História da Educação. In: XAVIER, L.; TAMBARA, E.; PINHEIRO, A. C. F. (Org.). História da Educação no Brasil: Matrizes interpretativas, abordagens e fontes predominantes na primeira década do século XXI. Vitória: Edufes, 2011.p. 147-166

WALTER, Tatiana et al. Por uma racionalidade ambiental: Reflexões acerca dos regramentos propostos para a pesca da tainha no estuário da Lagoa dos Patos/RS. Ambiente \& Educação, Rio Grande, v. 23, n.1, p. 31-53, Jul./Dez. 2018. DOI: https://doi.org/10.14295/ambeduc.v23i1.7415. Disponível em: https://periodicos.furg.br/ambeduc/article/view/7415/5293. Acesso em: 10 setembro 2019.

Submetido em: 20-01-2020. Publicado em: 17-04-2020. 